\title{
MEMÓRIAS DE TROIA: "NO SECOND TROY” DE WILLIAM BUTLER YEATS EM CANÇÕES POPULARES IRLANDESAS
}

\author{
MEMORIES OF TROY: "NO SECOND TROY” BY WILLIAM BUTLER YEATS IN \\ IRISH POP MUSIC
}

Mariese Ribas Stankiewicz ${ }^{1}$

\begin{abstract}
Resumo: Este artigo aborda as canções "Troy" de Sinéad O'Connor (1987) e "Yeat's Grave" de Dolores O'Riordan (1994) no contexto dos estudos culturais e como uma forma de apropriação do poema "No Second Troy", de William Butler Yeats, considerando, entre outros aspectos, os traços ideológicos dos diálogos entre eles. Assim, um dos objetivos principais é o de verificar como os autores trabalham com suas lembranças de acontecimentos passados e como suas compreensões dessas memórias estão em constante revisão e se misturam com novas tendências da contemporaneidade. Nesse sentido, a teoria de Mikhail Bakhtin, especificamente, suas ideias de dialogismo e seu conceito de discurso bivocal podem ajudar com algumas reflexões sobre como Sinéad e Dolores mostram situações históricas particulares em suas músicas que fazem o ouvinte prestar atenção à condição de presença / ausência da mudança que permeia a memória cultural de um povo.
\end{abstract}

Palavras-Chave: Literatura Irlandesa; Estudos Culturais; Dialogismo; Bivocalidade.

Abstract: This paper addresses Sinéad O'Connor's "Troy" (1987) and Dolores O'Riordan's "Yeat's Grave” (1994) in the context of cultural studies and as a way of appropriation of William Butler Yeats's poem "No Second Troy", considering, among other aspects, the ideological traits of the dialogues among them. Thus, one of the main objectives is to verify how the authors work on their memories of past happenings and how their understanding of those memories are in constant revision and blend with new fashions and trends of contemporaneity. In this sense, Mikhail Bakhtin's theory, specifically, his ideas on dialogism and his concept of double-voiced discourse may help with some reflections on how O'Connor and O'Riordan show particular historical situations in their songs that make the listener pay attention to the condition of presence / absence of change that permeates the cultural memory of a people.

Keywords: Irish Literature; Cultural Studies; Dialogism; Double-Voicing.

\section{Introdução}

William Butler Yeats foi um conspícuo poeta do final do século XIX e início do século XX, um "último romântico", como ele se autodenominava, vivendo na turbulência e

\footnotetext{
${ }^{1}$ Professora Adjunta da Universidade Tecnológica Federal do Paraná (DALET-UTFPR), nas subáreas de Literaturas de Língua Inglesa e de Ensino de Língua Inglesa; Professora do Programa de Pós-Graduação em Letras (PPGL-UTFPR); Coordenadora do Programa Institucional de Bolsa de Iniciação à Docência - PIBID (UTFPR/CAPES); Mestre em Inglês e Literaturas Correspondentes (UFSC); Doutora em Estudos Linguísticos e Literários em Inglês (USP-FFLCH). marieser@utfpr.edu.br
} 


\section{Revista InterteXto / ISSN: 1981-0601}

v. 10, n. 2 (2017)

instabilidade do modernismo e do período das guerrilhas civis entre a Irlanda e a GrãBretanha. Seus esforços para se engajar em uma literatura distintamente irlandesa, juntamente com escritores contemporâneos e futuros, são um traço representativo para o desenvolvimento deste estudo. A história dos movimentos na política e na literatura e a voz nacionalista em seus poemas, como em "To Ireland in the Coming Times", em "Under Ben Bulben", entre tantos outros, criaram uma zona conflituosa de diálogos interpretativos entre os mais variados críticos, entre eles, a verificação de seus poemas como um "legado" para futuros escritores e artistas na Irlanda.

Como a consciência histórica também pode incluir um conjunto de memórias dos tempos passados transformadas por um povo, a chegada das próximas gerações de escritores reúne um misto de desenvolvimentos que, embora totalmente modernos, combinam, por vezes, as fracas vozes que vem do passado. Em Facing the Music: Irish Poetry of the Twentieth Century, Eamon Grennan dedica o capítulo "Careless Father: Yeats and His Juniors" para discutir as mais diversas reações dos escritores irlandeses em relação à "pretensão", "cuidado", de Yeats em poemas como "Under Ben Bulben", por exemplo. No entanto, suas considerações são submetidas a partir de pontos de vista particulares, preenchidas por seus próprios preconceitos e analisadas de acordo com seus contextos históricos. Poetas contemporâneos de Yeats, os quais viveram ao meio de muitos ajustes internos na política da nova república, trabalharam exaustivamente para ter suas próprias vozes. Austin Clarke, cujas aparências yeatsianas e joyceanas em seus poemas são frequentes, escreveu que o relacionamento de Yeats com "a geração mais nova de poetas [...] na Irlanda foi [como] a de um enorme carvalho que, é claro, manteve[-os] à sombra" ${ }^{2}$ (GARRATT, 1986, p. 133) e aponta que alguns escritores afirmam que Yeats até mesmo "prejudicou [...] a geração mais nova de escritores na Irlanda"3 (Idem, p. 134). O sentimento de "permanência" em Yeats foi o que fez com que a sensação de "sombra" se tornasse excessivamente escura. Dessa maneira, as respostas de escritores irlandeses contemporâneos ao trabalho de Yeats têm divergido muito. Alguns apresentam confrontações abertas em relação às suas ideias, que geralmente levam a tentativas de

\footnotetext{
2 "[T]he younger generation of poets [...] in Ireland [was] rather like [that of] an enormous oak-tree which, of course, kept [them] in the shade" (GARRATT, 1986, p. 133).

3 "[Yeats] did harm [...] to the younger generation of writers in Ireland" (Idem, p. 134).
} 


\section{Revista InterteXto / ISSN: 1981-0601}

v. 10, n. 2 (2017)

separá-lo da literatura contemporânea (Idem, p. 16), enquanto outros, ao admirá-lo, estabelecem um diálogo amistoso entre seus trabalhos e as temáticas e estilo do poeta. Esta situação criou um dilema que se concentra em questões de como permanecer irlandês e não ser lembrado pelo trabalho de Yeats, ou de como lidar com assuntos irlandeses na literatura longe de sua obra.

Eamon Grennan fala de um Yeats solitário que pertence ao passado ou à sua própria tradição. De acordo com este crítico, Yeats falaria com poetas que fazem parte de uma "ficção coletiva", e que dependem igualmente de um público fictício, que aparece em contraste com uma "audiência real" (Idem, p. 135). Em meio a tantas posições diferentes, podemos verificar que a voz do poeta ainda está presente em textos literários, artísticos, dramatúrgicos e musicais contemporâneos. O entendimento e a memória do passado presente no imaginário coletivo são fatores que caracterizam os laços nacionais de um determinado povo. O conhecimento popular implica a forma como uma comunidade nacional responde a memórias públicas nacionais e históricas, ou seja, a forma como reflete e analisa essas memórias e, consequentemente, como emprega as inferências em considerações sobre eventos contemporâneos na sociedade. Por meio desse processo, a consciência histórica avança e é transmitida através da comunicação social - através de mensagens transmitidas pela comunidade nacional. Por isso, como no caso das perspectivas atuais, o futuro evolui, na medida em que a compreensão e a memória do passado estão em constante revisão em todo o contexto nacional de um povo.

Dessa maneira, imbuídos obviamente pela consciência histórica, compositores de música popular irlandesa evocam a transformação de valores passados em algo moderno e presente. À luz dos conceitos de heteroglossia e de bivocalidade de Mikhail Bakhtin, este artigo trata de análises de interações dialógicas temáticas entre o poema de Yeats, "No Second Troy" e letras de compositoras irlandesas do século XXI: "Troy" de Sinéad O'Connor e "Yeat's Grave" de The Cranberries, enquanto verifica semelhanças e diferenças entre eles. De qualquer forma, as semelhanças (interações amigáveis entre linguagens, ideologias e quadros temáticos) e diferenças (relações discordantes entre elas) estão indubitavelmente presentes entre outros poemas e letras de autores e compositores irlandeses. Isso significa que temas específicos, atitudes políticas, ideias e mesmo esse "vocabulário musical, 
profundo"4 (YEATS, 1999, p. 138), ao qual o poeta se referiu uma vez, estão presentes em letras de músicas contemporâneas, combinadas com uma série de outras características diferentes e determinadas por mudanças sociais que inevitavelmente têm afetado a redação de todos os textos na sociedade irlandesa.

No decorrer do século $\mathrm{XX}$, a Irlanda foi deixando de ter aquela posição provinciana com a literatura e com as artes (assim como aconteceu com a economia e com o desenvolvimento social e político) para se inserir mundialmente em uma atividade literária globalizante. A retórica, que caracterizou disputas entre estilos de escritores e da sociedade em que viviam, deu mais espaço para a transformação literária e artística. A voz lírica do país transformou-se na voz cultural de uma nação inteira, de uma forma consciente. No entanto, embora envolvidos em tendências pós-modernas, os compositores ainda relembram os últimos cem anos de atividade poética, principalmente no que diz respeito aos desenvolvimentos nacionalistas no início do século passado.

Obviamente, hoje em dia, parece que obras de compositores contemporâneos já não se assemelham aos da "roseira" de Yeats, e a tradição que ele desejava não parece ter sido continuada, ou seja, o profundo e críptico desenvolvimento literário de sua carreira jamais foi trilhado na íntegra. No entanto, duas características persistentes da tradição irlandesa contemporânea como um todo que podem ser verificadas nas letras musicais são a constância com que as gerações sucessivas de compositores pesquisaram seus passados literários e seus interesses em trazer a história da Irlanda para um nível consciente de compreensão. Aqui, a voz original do meio adormecido "Under Ben Bulben" ainda é ouvida. Ao ler, reler e reescrever a história literária através de seus passos divididos e diferentes, compositores contemporâneos tem continuamente levantado a questão do sentido imaginário do passado como parte de sua cultura atual.

Os poemas de amor de Yeats estiveram presentes no rock irlandês, na medida em que representam uma releitura de seu passado literário e vida pessoal. Sua profunda história de amor mal sucedida com a ardente e revolucionária anglo-irlandesa Maud Gonne é lembrada de vez em quando, vividamente questionada e investigada por historiadores e biógrafos de Yeats. Como este tema é frequente na música popular, roqueiros irlandeses

\footnotetext{
4 “[S]ensuous, musical vocabulary" (YEATS, 1999, p. 138.)
} 
encontraram na poesia de Yeats um componente histórico que também é uma forma de animar o passado cultural. Além disso, de acordo com M. L. Rosenthal,

Yeats também foi o poeta que, enquanto muito do seu próprio tempo na Irlanda, falava melhor para as pessoas de todos os países. [...] O elemento da música está sempre presente no trabalho deste poeta, não só na sua escrita puramente lírica com raízes óbvias em canções folclóricas, mas também em sua escrita mais intelectual e retórica. Por toda parte, também, o tema da música e do canto se repete constantemente. ${ }^{5}$ (YEATS, 1986, p. xv)

Embora criticamente reverenciado e popular na Irlanda, a maioria dos poemas de Yeats exploram uma terminologia pessoal e simbólica, que requer estudos elaborados e extensos de seus escritos artísticos e intelectuais. "No Second Troy", que integra o livro The Green Helmet and Other Poems (1910), contém linguagem simbólica e a presença da história irlandesa em paralelo à mitologia grega. Além disto, muitas vezes este poema foi analisado de acordo com suas autobiografias e biografias. Consequentemente, a Helena do poema parece ser a representação alegórica de Maud Gonne. Em consideração ao grande número de estudos que apontam para essa possibilidade, e da consciência histórica irlandesa que atualizou muitas memórias de Yeats, parece que existe um senso comum sobre a presença de Maud Gonne no poema e sobre o fato de que ela pode ser a Helena de Troia, a que Yeats se refere.

"No Second Troy" é lembrado pelo amor de longa data de Yeats por Maud Gonne. Não obstante, o seu tema é sobre uma mulher, cujas ações foram desaprovadas por um eu lírico infeliz, que pondera sobre a possibilidade de culpá-la por essas mesmas ações. A mulher - supostamente uma Helena moderna - encheu a vida do eu lírico com sofrimento e infortúnio, e foi enredada em "formas violentas", que não são abertamente declaradas:

Por que eu deveria culpá-la por ela ter preenchido os meus dias

Com miséria, ou que ela teria por fim

Ensinado a homens ignorantes as formas mais violentas,

Ou lançado pequenas ruas sobre as grandes,

\footnotetext{
5 "Yeats was also the poet who, while very much of his own day in Ireland, spoke best to the people of all countries. [...] The element of song is always present in this poet's work, not only in his purely lyrical writing with obvious roots in folksong but also in his more intellectual and rhetorical writing. Everywhere, too, the theme of music and singing recurs constantly" (YEATS, 1986, p. xv).
} 


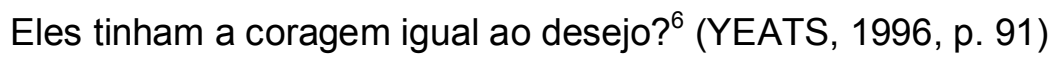

A exposição do problema aparece como uma questão retórica. No entanto, perguntando a respeito de um motivo para culpar a mulher por seu mau comportamento, o tom do eu lírico é exatamente o oposto, ou seja, aquele de lhe proporcionar o perdão. O poema é uma meditação sobre uma característica específica da mulher, com a qual o eu lírico não está à vontade. Essa Helen - aparentemente uma mulher bonita - reuniu a atenção de homens ignorantes para levá-los às lutas e à violência. Ela escolheu as pequenas ruas - pessoas e questões de menor valor - em vez das grandes.

O sujeito lírico menciona um grupo de pessoas, "eles", aparentemente os "homens ignorantes", cujos sentimentos de desejo por essa mulher, ele os compara aos de coragem. $\mathrm{Na}$ verdade, o eu lírico ironicamente sugere que sua coragem não é tão forte quanto seu desejo. Há uma sequência de três perguntas dirigidas ao leitor. O sujeito lírico reflete sobre a viabilidade de uma vida pacífica para aquela mulher que tem uma mente nobre e uma beleza para ser reverenciada. Em outra questão, ele se consola, dizendo que não havia outra coisa que poderia ter feito, já que ela é "o que é":

\footnotetext{
O que poderia torná-la pacífica com uma mente

Que a nobreza fez simples como fogo,

Com a beleza como um arco retesado, de um tipo

Que não é natural em uma época como esta,

Sendo altiva e solitária e mais exigente?

Por que, o que ela poderia ter feito, sendo o que ela é?

Houve uma outra Troia para ela queimar? ${ }^{7}$ (Idem, p. 91)
}

A última pergunta tem a resposta no título: não, não havia "nenhuma outra Troia". Na história grega, Troia foi completamente destruída durante a guerra que travou contra Esparta, quando milhares de soldados lutaram contra o sequestro de uma mulher infiel. Na situação verificada no poema, essa outra mulher realizou uma história semelhante, sem ter o mesmo fim. O uso do termo "Troia" por Yeats pode ser parte de um ponto irônico. Mesmo com todos

\footnotetext{
6 "Why should I blame her that she filled my days / With misery, or that she would of late / Have taught to ignorant men most violent ways, / Or hurled the little streets upon the great, / Had they but courage equal to desire?" (YEATS, 1996, p. 91).

7 "What could have made her peaceful with a mind / That nobleness made simple as a fire, / With beauty like a tightened bow, a kind / That is not natural in an age like this, / Being high and solitary and most stern? / Why, what could she have done, being what she is? / Was there another Troy for her to burn?" (Idem, p. 91).
} 
esses atributos, a mulher não foi glorificada pelas ações heroicas daqueles que ela persuadiu; talvez não por sua própria culpa, uma vez que esse lugar que apenas parece ser Troia não faz parte de um passado nobre e heroico.

Há muitas especulações sobre quem é a mulher em "No Second Troy". Talvez, ela possa ser Cathleen ni Houlihan, a personificação da Irlanda. De qualquer forma, o poema não é explícito sobre quem são essas pessoas. No entanto, a maioria das análises críticas estabelecem paralelos entre Yeats e Maud Gonne, uma vez que foi difícil evitar evidências biográficas. Rosenthal considera que "o poema projeta (mas certamente não especifica) uma situação dramática em que o eu lírico é um homem como Yeats e o assunto, uma mulher como Maud Gonne"8 (YEATS, 1986, p. xxx). As semelhanças entre arte e vida residem em informações históricas sobre seu caso de amor nunca resolvido e sobre suas então atividades revolucionárias. Em um manuscrito, Yeats descreveu suas impressões sobre Maud Gonne:

\begin{abstract}
Nunca tinha pensado em ver uma mulher desta época tão grande beleza, uma beleza pertencente a grandes poetas e fotos famosas de [?] de algum passado lendário. Uma compleição como a de flor de uma maçã e, no entanto, uma forma que tinha a beleza de [delineamentos] que Blake chamou de beleza mais alta porque é imutável desde a juventude até a maturidade, e uma estatura tão grande que parecia ter descido do Olimpo. Seus movimentos combinavam com sua forma e eu entendi finalmente por que os poetas da antiguidade, onde enaltecemos sorriso e os olhos dizem, ao invés disto, que ela caminhava como uma deusa ... [...] E, de repente, ela seria ... caiu em alguma forma de atividade política que parecia à minha mente sem direção, como o movimento de um esquilo em uma roda. ${ }^{9}$ (YEATS, 1999, p. 442-43)
\end{abstract}

Essas e outras características biográficas, que correspondem às ideias que podem ser lidas em "No Second Troy", forneceram a variedades de críticos literários uma mesma linha de interpretação.

\footnotetext{
8 "[T] he poem projects (but certainly does not specify) a dramatic situation in which the speaker is a man something like Yeats, the subject a woman something like Maud Gonne" (YEATS, 1986, p. xxx).

${ }^{9}$ I had never thought to see in living woman so great beauty, a beauty belonging to great poets, and famous pictures of [?] some legendary past. A complexion like the blossom of an apple and yet a form that had the beauty of [lineaments] which Blake called the highest beauty because it is changeless from youth to age, and a stature so great she seemed to have walked down from Olympus. Her movements matched her form and understood at last why the poets of antiquity, where we would praise smile and eyes say rather she walked like a goddess... [...] And then of a sudden, she would be... hurried into some form of political activity that seemed to my mind without direction, like the movement of a squirrel on a wheel. (YEATS, 1999, p. 442-43)
} 


\section{Revista InterteXto / ISSN: 1981-0601}

v. 10, n. 2 (2017)

Ao escrever sobre o poema, Terence Brown verifica o curso revolucionário dos ativistas políticos irlandeses e afirma que "forças emancipadoras perturbadoras, por esta razão, são lançadas pela imagem neste poema de mulher / Gonne como guerreira cavalheiresca, sobre a qual o poeta é ambivalente"10 (BROWN, 2001, p. 184). Harold Bloom explica que "a sequência de The Green Helmet é composta principalmente de poemas conscientemente retrospectivos sobre o relacionamento perdido com Maud Gonne"11 (BLOOM, 1972, p. 168) e acrescenta uma citação de Yvors Winters, que afirma que Maud Gonne "é um caso especial, pois Yeats estava apaixonado por ela; mas sua equivalência de Maud Gonne com Deirdre, Helena de Troia e Cathleen ni Houlihan participam de própria dramatização de Yeats"12 (WINTERS apud BLOOM, 1972, p. 169). Certamente, essas visões entram no contexto histórico irlandês de uma forma a tornarem-se "verdadeiras", na medida em que as pessoas vivificam suas memórias da história da vida de Yeats combinadas com crenças populares e críticas sérias. É isso que parece acontecer com algumas canções populares irlandesas.

As cantoras e compositoras Sinéad O'Connor e Dolores O'Riordan de The Cranberries adicionaram "No Second Troy" aos ritmos e temas das músicas "Troy" e "Yeat's Grave", respectivamente. No entanto, o poema exibe diferentes pontos de convergência em cada música. Os diálogos textuais nas letras aparecem como um símbolo de bivocalidade ou como homenagem a Yeats. Além disso, o cruzamento de línguas, atitudes ou estilos, que resulta em um diálogo entre pontos de vista (BAKHTIN, 2002, p. 76), descreve algumas perspectivas sobre leituras variadas desse poema de Yeats, que se tornaram visivelmente relevantes para músicos irlandeses contemporâneos. "No Second Troy" é aplicado às músicas, de acordo com a ideia do romance entre Yeats e Maud Gonne. Stuart Bailie afirma que, após um período de amadurecimento do processo de composição de letras, Dolores, vocalista e compositora de The Cranberries,

\footnotetext{
10 "Disturbing emancipatory forces therefore are released by the image in this poem of woman/Gonne as chivalric warrior, about which the poet is ambivalent" (BROWN, 2001, p. 184).

11 "[T] $T$ he sequence of The Green Helmet is composed mostly of consciously retrospective poems on the lost relationship with Maud Gonne" (BLOOM, 1972, p. 168).

${ }^{12}$ Maud Gonne "is a special case, for Yeats was in love with her; but his equation of Maud Gonne with Deirdre, Helen of Troy, and Cathleen ni Houlihan partakes of his dramatization himself" (WINTERS apud BLOOM, 1972, p. 169).
} 
estava encontrando muitos novos assuntos para tratar. Por exemplo, Dolores escreveu sobre Yeats e seu caso de amor condenado com a revolucionária Maud Gonne [em 'Yeat's Grave'] (Sinéad O'Connor também estava obcecada com esta história, usando-a como base para seu single de estreia, 'Troy'). ${ }^{13}$ (BAILIE, 1995, p. 65)

"Troy" e "Yeat's Grave" são analisados de acordo com dois critérios principais: em primeiro lugar, ao verificarem-se as interações dialógicas, as consciências históricas de Yeats e dos compositores contemporâneos são eminentemente consideradas. Suas memórias de acontecimentos passados e sua compreensão dessas memórias estão em constante revisão e se misturam com novas tendências dos dias atuais. Além disto, tendo como suporte teórico os estudos de Bakhtin sobre o romance - ou, especificamente, sobre os poemas romancizados - a questão das interações dialógicas - observada através dos usos que os compositores fazem dos poemas de Yeats - é verificada de acordo com a elaboração de Bakhtin dos conceitos de heteroglossia e de bivocalidade. Segundo Bakhtin, os romances (e os gêneros romancizados, como os poemas sociais) "podem ser definidos como uma diversidade de tipos discursivos sociais (às vezes até mesmo diversidade de linguagens) e uma diversidade de vozes individuais, artisticamente organizadas"14 (BAKHTIN, 2002, p. 262). Nesse sentido, através de seus textos, a voz de Yeats e as dos músicos são ouvidas em um pano de fundo do qual outras vozes participam.

Ao tentar elaborar uma teoria para o romance e para os gêneros romancizados, além das estilísticas poéticas e alegando que as teorias do romance existentes não se constituíam de maneira completas ou não descreviam a totalidade do romance, Bakhtin enfoca nos gêneros romancizados, examinando uma "multiplicidade socialmente heteroglota" 15 de seus discursos, isto é, a "orientação dialógica de uma palavra entre outras palavras (de todos os tipos e graus de alteridade) [que] cria um novo e significativo potencial artístico no discurso" 16 (Idem, p. 275). De acordo com Bakhtin, todos procuramos produzir sentido não dentro de um

\footnotetext{
13 “Dolores O'Riordan was finding lots of new subjects to cover. For example, Dolores wrote about Yeats and his doomed love affair with revolutionary Maud Gonne [in 'Yeat's Grave'] (Sinéad O'Connor was also obsessed with this story, using it as the basis for her debut single, 'Troy')" (BAILIE, 1995, p. 65).

14 "TThey] can be defined as a diversity of social speech types (sometimes even diversity of languages) and a diversity of individual voices, artistically organised" (BAKHTIN, 2002, p. 262).

15 "[S]ocially heteroglot multiplicity" (Idem, p. 275).

16 "[D]ialogic orientation of a word among other words (of all kinds and degrees of otherness) [that] creates new and significant artistic potential in discourse" (Idem, p. 275).
} 
sistema linguístico isolado, mas contra um fundo discordante dos enunciados dos outros sobre o mesmo tema, a palavra em linguagem é, em parte, de outra pessoa. Torna-se "própria" apenas quando

o falante a ocupa com sua própria intenção, seu próprio sotaque, [...] a palavra não existe em uma linguagem neutra e impessoal [...], mas sim na boca de outras pessoas, nos contextos de outras pessoas, servindo as intenções de outras pessoas: é a partir daí que é preciso tomar a palavra e torná-la própria. ${ }^{17}$ (Idem, p. 293-94).

Ou seja, para tornar uma palavra verdadeiramente sua, o escritor entra em "um ambiente dialogicamente agitado e tenso de palavras estrangeiras, julgamentos de valor e sotaques", e procura negociar essa tensão através da "assimilação seletiva das palavras dos outros"18 (Idem, pp. 276, 341). Bakhtin explica a escrita como um processo de negociação entre autoridades pessoais e públicas e como uma orquestra daquelas vozes que falam dentro e fora de certos contextos. As palavras do escritor ecoam com as vozes dos outros, como Bakhtin diria, com uma polifonia de outros pontos de vista, nuances, contextos e intenções, e é ao orquestrar essa polifonia que o escritor faz significados. E uma vez que essas palavras nascem no diálogo e são moldadas através da interação com outras vozes, o que o escritor cria através do idioma não é uma única voz, mas muitas que servem ao propósito de suas próprias intenções.

No repertório musical de Sinéad, os temas variam desde a descoberta atemporal do folclore celta até temas políticos como a guerra e problemas sociais e o dilema universal do amor jovem. O tema de sua música "Troy" é uma história insidiosa de amor, traição e desespero. O enredo é sobre pequenos momentos domésticos com mudanças repentinas para reflexões lacônicas, em que aparecem dois grandes símbolos derivados da mitologia: a Fênix egípcia e a Troia grega. Da mesma forma, o símbolo da Fênix aparece em algumas das descrições de Yeats de Maud Gonne. Em um manuscrito inédito, Yeats escreveu sobre a Fênix:

\footnotetext{
17 "[T] he speaker populates it with his own intention, his own accent, [...] the word does not exist in a neutral and impersonal language [...], but rather it exists in other people's mouths, in other people's contexts, serving other people's intentions: it is from there that one must take the word, and make it one's own" (Idem, p. 293-94).

18 "[A] dialogically agitated and tensionfilled environment of alien words, value judgments and accents" [...] "selectively assimilating the words of others" (Idem, pp. 276, 341).
} 
Qual será o final? Ela tem a mim por inteiro ... Nunca estive mais profundamente apaixonado, mas meu desejo, sempre forte, deve ir para outro lugar ... ela é minha inocência e eu sua sabedoria. Madura, ela era uma fênix e lutei contra ela, mas agora ela é minha filha mais do que namorada ... mas no ninho de fênix ela renasce com todo o seu poder de torturar e dar prazer, descartar e enobrecer. Ela seria cruel se ela não fosse uma criança, que sempre pode dizer 'Você não vai sofrer porque eu rezarei' ${ }^{19}$. (YEATS apud BROWN, 2001, p. 174)

Em "Troy", os dois símbolos são organizados ao nível do discurso de Sinéad, ou seja, eles não representam os significados originais inferidos por Yeats, mas sim eles carregam aspectos modernizados e modificados compreendidos pelo público contemporâneo.

Bakhtin afirma que "assim que a voz de uma outra pessoa, o sotaque de uma outra pessoa, a possibilidade do ponto de vista de uma outra pessoa rompem através desse jogo do símbolo, o plano poético é destruído e o símbolo é traduzido para o plano da prosa”, isto é, o símbolo transmite "a própria voz de alguém" e refuta "a própria intenção recente de uma pessoa"20 (BAKHTIN, 2002, p. 328). "Troy" e "No Second Troy" exibem histórias distintas, e os símbolos são bivocais, ou seja, eles representam a voz de Sinéad, ao tentar associá-los à vida de Yeats; e a voz da persona, que vive um final terrível de uma relação amorosa. Além disso, o símbolo "Troia" representa uma pluralidade de vozes, considerando outras narrativas do mito de Helena.

Embora não haja mudanças substanciais no tom, os símbolos utilizados por Sinéad são estilizados - são usados para um dilema casual, algo que pode acontecer a todos aqueles que estão nas relações amorosas: a angústia da separação. Na letra da canção, os símbolos não transmitem seus significados originais, mas representam o fracasso das relações amorosas, que implicitamente sugerem o romance de Yeats e Maud Gonne, ou um destino semelhante. Sinéad não considera o enredo de "No Second Troy", mas, propositalmente, parece emprestar símbolos que já possuem uma forte conotação histórica.

\footnotetext{
19 "What end will it have? She has all myself... I was never more deeply in love, but my desire, always strong, must go elsewhere... she is my innocence and I her wisdom. Of old she was a phoenix and I fought her, but now she is my child more than sweetheart... but in the phoenix nest she is reborn in all her power to torture and delight, to waste and to en[n]oble. She would be cruel if she were not a child, who can always say 'You will not suffer because I will pray"' (YEATS apud BROWN, 2001, p. 174).

20 "[A]s soon as another's voice, another's accent, the possibility of another's point of view breaks through this play of the symbol, the poetic plane is destroyed and the symbol is translated onto the plane of prose [...] one's own voice [...] one's own fresh intention" (BAKHTIN, 2002, p. 328).
} 
Além disso, "No Second Troy" Ihe fornece uma referência textual simbólica mais abrangente a ser explorada em "Troy". Assim, aqueles que escutam os símbolos usados por Yeats e conhecem seus atributos teriam uma noção exata daquilo a que ela se refere.

Com a apresentação simultânea de filosofias conflitantes e estilos entre "Troy" e "No Second Troy", os símbolos em "Troy" (Fênix e Troia) referem-se tanto à própria persona quanto a seu amado. No entanto, a persona chama a voz do poeta, cantando: "Você vai se levantar / Você vai voltar / A fênix da chama"21 (O'CONNOR, 1987) e, em seguida, exercita sua fênix interior:

Mas eu ascenderei
E retornarei
A fênix da chama
Eu aprendi que levantarei
E você me verá voltar
Sendo o que sou
Não há nenhuma outra Troia
Para eu queimar ${ }^{22}$ (Idem)

"Sendo o que sou" ecoa "[...] sendo o que ela é" (YEATS, 1996. p. 91), enquanto o verso acima também se assemelha à sequência: "Sendo o que você é / Não há outra Troia / Para você queimar"23 (O'CONNOR, 1987). A persona e o seu amado são versões do "objeto do amor" que Maud Gonne significou para Yeats. A consciência histórica de Sinéad de um passado particular correlaciona-se com o significado que esses símbolos atualmente representam. A ideia da compositora sobre o significado do símbolo "Troia", bem como a ideia do próprio poeta (em um sentido diferente), é relevante de acordo com a expressão de propósitos específicos. Como Bakhtin ressalta, a

linguagem do autor luta para superar a 'literaridade' superficial dos estilos moribundos, ultrapassados e das linguagens atadas às tendências de cada período; [a linguagem] luta para se renovar recorrendo a elementos fundamentais da linguagem popular. ${ }^{24}$ (BAKHTIN, 2002, p. 49)

\footnotetext{
21 “You will rise / You'll return / The phoenix from the flame” (O'CONNOR, 1987).

22 "But I will rise / And I will return / The phoenix from the flame / I have learned I will rise / And you'll see me return / Being what I am / There is no other Troy / For me to burn" (Idem).

${ }_{23}$ "Being what you are / There is no other Troy / For you to burn" (O'CONNOR, 1987).

24 "[The] language of the author strives to overcome the superficial 'literariness' of moribund, outmoded styles and fashionable period-bound languages; it strives to renew itself by drawing on the fundamental elements of folk language" (BAKHTIN, 2002, p. 49).
} 
Certamente, as palavras de Bakhtin servem aos textos tanto de Sinéad quanto o de Yeats, já que este também estiliza o símbolo "Troia".

Embora este símbolo também seja encontrado em 'Yeat's Grave', implicando a ideia do caso que Yeats teve com Maud Gonne, a citação de "No Second Troy" presente em "Yeat's Grave" aparece de forma diferente. A música é um tributo a Yeats como poeta e como homem. The Cranberries refere-se à vida do poeta e ao seu amor por Maud Gonne, sem ajustar subjetivamente o símbolo de "No Second Troy", como é verificado em "Troy". Em "Yeat's Grave", o eu lírico declara-se consciente do que Yeats representa para a cultura irlandesa. Os sentimentos do eu lírico são os de um retaliador por causa da indiferença de Maud Gonne, vitalizando a memória de Yeats e de sua poesia.

The Cranberries concentrou-se em músicas que falam sobre o sonho e a ternura. Contudo, além dos temas suaves, os temas de guerra e anti-guerra acabam por se combinar constantemente com a história irlandesa. Geralmente, esses temas exibem vínculos entre mundos físicos e espirituais, ou entre a vida e a morte. Há um velho ditado gaélico que afirma que "há alegria no sofrimento" 25 (SAWYERS, 2000, p. 18), traço cultural que tem sido amplamente representado na literatura, nas artes e em músicas irlandesas é bastante. June Sawyers explica a associação existente entre tristeza e melodia, que é recorrente na música celta, dizendo que

a música dos gaélicos expressa essa turbulência interior [de serem tanto aprisionados como rejuvenescidos pelo passado]. Você pode ouvir isso nos lamentos profundamente tristes e nas ansiedades lúgubres dos ares melancólicos. Mas também há uma leveza, até mesmo uma qualidade impudente, que se atreve a comemorar as emoções mistas que vêm com a vida. É uma música de grande tristeza e tragédia requintada, mas também de notável alegria e espírito vibrante. ${ }^{26}$ (SAWYERS, 2000, p. 94)

"Yeat's Grave" não é um lamento; é uma mistura de leve tristeza com a dramatização de Yeats em seu túmulo falando com alguém. A letra sugere a presença física ou espiritual de

\footnotetext{
25 "[T]here is a joy in grief" (SAWYERS, 2000, p. 18).

26 "The music of the Gael expresses this inner turmoil [of being both trapped and rejuvenated by the past]. You can hear it in the profoundly sad laments and in the mournful strains of melancholy airs. But there is also a lightness, a randy quality even, that dares to celebrate the mixed emotions that come with living. It is a music of great sorrow and exquisite tragedy but also of unremarkable joy and tremendous spirit" (SAWYERS, 2000, $p$. 94).
} 


\section{Revista InterteXto / ISSN: 1981-0601}

v. 10, n. 2 (2017)

Yeats com um personagem desconhecido, possivelmente um que vai visitar seu túmulo. Ela interpreta Yeats conversando com um visitante e recitando "No Second Troy" com um tom baixo e constantemente interrompida por outros instrumentos musicais e por seu próprio canto.

O uso de "No Second Troy" por Dolores em partes específicas da música obviamente não é neutro, uma vez que o poema ressoa com informações culturais e ideológicas. A música sugere a presença de um personagem nacional inseparável da cultura irlandesa. No entanto, como ela canta sobre Yeats no túmulo, emblemático daqueles que já se foram, criase uma situação duvidosa de que o poeta pode ser ou não ainda relevante para a arte, a literatura e a música da cultura irlandesa atual. Assim, a situação oscila entre ligação e desconexão, entre lembrança e esquecimento. Isso aparece na letra da música como um discurso bivocal - a posição de duas consciências distintas dentro de uma única ideia (BAKHTIN, 2002, p. 324-25). Podemos ouvir com as palavras de Dolores não apenas uma voz, mas muitas: aquelas vozes que reivindicam a presença do trabalho de Yeats nas artes irlandesas - forças de continuidade - e as vozes que representam forças de descontinuidade. Dolores não ignora nem silencia essa variedade de vozes, mas as usa como fundo, como uma tensão necessária contra a qual seus significados podem ser resgatados de maneira mais completa.

A música trata da questão da morte, tanto real quanto metafórica, de Yeats. O sujeito lírico inicia com uma frase retórica e irônica: "Silenciado pela morte no túmulo / William Butler Yeats não pôde se controlar", isto é, não pôde resistir à tentação de voltar a falar, implicando que Yeats não está morto. Sem alterações na voz da cantora, ela representa Yeats indagando uma pessoa sobre o motivo de sua visita. O discurso de Yeats é desarticulado, como se fizesse parte do pensamento daquela pessoa. No início, suas perguntas parecem uma queixa: "Por que você ficou aqui? Você ficou chocado a tempo? / Mas eu sei agora / Por que você se sentou aqui? / Em um túmulo"27 (THE CRANBERRIES, 1994). Através da voz Yeats, o sujeito lírico pergunta ao visitante sobre suas pesquisas a respeito dele, uma vez que ele está morto agora, apesar de parecer vivo. A canção trata da importância de Yeats para o mundo irlandês contemporâneo. Ao organizar a letra da música dessa forma, Dolores

\footnotetext{
27 "Silenced by death in the grave / William Butler Yeats couldn't save / Why did you stand here? / Were you sickened in time? / But I know by now / Why did you sit here? / In a grave" (THE CRANBERRIES, 1994).
} 
desenvolve uma versão estilizada da linguagem daquilo que culturalmente conhecemos de Yeats que acaba se combinando com lamentos. Ao criar uma ficção de uma conversa entre Yeats morto e um visitante, em meio a ritmos melancólicos, desconcertados pelos ritmos do rock, Dolores cria uma interação dialógica com a poética de Yeats.

Além disso, Yeats conforta-se voltando ao visitante: "E você se senta aqui comigo / $\mathrm{Na}$ Isle Innisfree / E você está anotando tudo"28 (Idem), com a exata identificação de que o túmulo é, na verdade, seu livro de poemas que está sendo lido e estudado. A menção Isle Innisfree (uma ilha no oeste da Irlanda) é muito significativa nestes versos. Com esta imagem da letra da música, Yeats está nessa ilha, que uma vez ele descreveu como um lugar ideal de paz e beleza. Em suas Autobiografias, ele comenta: "Eu ainda tinha a ambição, formada em Sligo na minha adolescência, a de viver imitando Thoreau em Innisfree"29 (YEATS, 1999, p. 139). Esse lugar, descrito no poema "The Lake Isle of Innisfree", é a representação lírica de um templo de imaginação e sonho, enquanto retrata através da imagem da natureza um lugar perfeito onde viver. A partir da música, podemos verificar que o eu lírico imagina Yeats vivendo espiritualmente nessa ilha e que alguém está lá com ele, "[...] anotando tudo"30 (THE CRANBERRIES, 1994), isto é, querendo saber sobre ele e sobre sua vida. Ao mesmo tempo em que aparece ainda vivo em nossa contemporaneidade, o eu lírico lembra de sua relação com Maud Gonne: "Triste que Maud Gonne não pode ficar / Mas ela teve MacBride ${ }^{31}$ de qualquer forma"32 (THE CRANBERRIES, 1994). Na música, a cantora recita fracamente algumas linhas de "No Second Troy". O eu lírico aparentemente mostra ressentimento por Maud Gonne não ter amado Yeats. No entanto, ao trazer esse poema à luz, além da história amorosa de Yeats, Dolores traz uma parte da história da Irlanda que jamais foi esquecida: as querelas políticas entre a Irlanda e a Grã-Bretanha. A música é um tributo a Yeats e ao passado de lutas que se transformaram com as vozes de vários escritores, dramaturgos e

\footnotetext{
28 "And you sit here with me / On the Isle Innisfree / And you're writing down everything" (Idem).

29 "I had still the ambition, formed in Sligo in my teens, of living in imitation of Thoreau on Innisfree" (YEATS, 1999, p. 139).

30 “[...] writing down everything" (THE CRANBERRIES, 1994).

${ }^{31}$ John MacBride foi ativista politico e um dos líderes do Easter Rising. Casou-se com Maud Gonne, com quem teve uma filha Iseult.

32 "Sad that Maud Gonne couldn't stay / But she had MacBride anyway" (THE CRANBERRIES, 1994).
} 


\section{Revista InterteXto / ISSN: 1981-0601}

v. 10, n. 2 (2017)

poetas. É cantando ao lado de um poema inesquecível que Dolores estabelece um diálogo com o escritor.

Além de mostrar mensagens que são muitas vezes universais, letras de músicas comunicam experiências sociais manifestadas através de ressonância e poder. Textos musicais incorporam dinamismo e interação social, que crescem nas estruturas sociais de uma comunidade. O interesse em trazer a poesia de Yeats para a dinâmica social viva através da música reforça a importância de sua obra no contexto cultural e social irlandês. As análises dos diálogos presentes nas letras selecionadas levaram em consideração a heteroglossia e a bivocalidade proposta por Bakhtin. Ao trazer palavras de outros contextos, as cantoras adaptam-nos às suas próprias intenções, de modo que as enunciações constituem diferentes significados.

Dolores e Sinéad têm arranjos musicais distintos, mas ambas apresentam vocalização emocional e dramatizada, bem notada nos cantos célticos. Elas participam desse amálgama de melancolia, raiva e romance, geralmente encontrados na poética irlandesa. As duas cantoras, conscientemente ou inconscientemente, conectam-se a gostos e estilos populares, enquanto incluem a história das guerras e dificuldades sociais sofridas pela Irlanda em muitas de suas músicas. Seus textos sociais contam ao público sobre uma história revisitada constantemente pelos olhos atuais. A interpretação popular de "No Second Troy" que tem imortalizado os sentimentos profundos de Yeats pelo amor de sua vida, Maud Gonne, lembra ao leitor destas palavras de "Under Ben Bulben", em que Yeats aconselha jovens poetas: "Cantem os senhores e as senhoras alegres / que foram esculpidos na argila"33 (YEATS, 1996, p. 78-79).

\section{REFERÊNCIAS}

BAILIE, The Cranberries: in your head. Londres: UFO Music Books, 1995.

BAKHTIN, Mikhail. The dialogic imagination: four essays. Org. por HOLQUIST, Michael. Trad. por EMERSON, Caryl; HOLQUIST, Michael. Austin: U of Texas P, 2002.

BLOOM, Harold. Yeats. Nova York: Oxford UP, 1972.

\footnotetext{
33 "Sing the lords and ladies gay / That were beaten into the clay" (YEATS, 1996, p. 78-79).
} 
BROWN, Terence. The life of W. B. Yeats: a critical biography. Oxford: Blackwell Publishers, 2001.

GADAMER, Hans-Georg. Truth and method. Trad. por WEINSHEIMER, Joel; MARSHALL, Donald G. $2^{\text {a }}$ ed. Rev. Nova York: Continuum, 1999.

GARRATT, Robert F. Modern Irish poetry: tradition \& continuity from Yeats to Heaney. Califórnia: U of California P, 1986.

GRENNAN, Eamon. Facing the music: Irish poetry of the twentieth century. Omaha: Assn. of Jesuit UPs, 1999.

O'CONNOR, Sinéad. The lion and the cobra. CD. Ensign-Chrysalis, Londres, 1987.

SAWYERS, June S. The complete guide to Celtic music. Londres: Aurum P, 2000.

THE CRANBERRIES. No need to argue. CD. Island, Londres, 1994.

YEATS, William Butler. The collected poems of W. B. Yeats. Org. por FINNERAN, Richard. $2^{\mathrm{a}}$ ed. Nova York: Scribner, 1996.

- The collected works of W. B. Yeats: autobiographies. Org. por O'DONNELL, William H.; ARCHIBALD, Douglas N. V. 3. Nova York: Scribner, 1999.

- Selected poems and three plays of William Butler Yeats. Org. por ROSENTHAL, M. L. $3^{\mathrm{a}}$ ed. Nova York: Collier Books-Macmillan Publishing Company,1986.

Artigo recebido em setembro de 2017.

Artigo aceito em abril de 2018. 